\title{
IMPACT OF DIFFERENT QUALITY OF SERVICE MECHANISMS ON STUDENTS' QUALITY OF EXPERIENCE IN VIDEOCONFERENCING LEARNING ENVIRONMENT
}

\author{
Dr. Toni MALINOVSKI \\ Faculty of Information and Communication Technology, FON University \\ Skopje, Republic of Macedonia \\ Dr. Vladimir TRAJKOVIK \\ Faculty of Computer Science and Engineering, Ss. Cyril and Methodius University \\ Skopje, Republic of Macedonia \\ Dr. Tatjana VASILEVA-STOJANOVSKA \\ Faculty of Computer Science and Engineering, Ss. Cyril and Methodius University \\ Skopje, Republic of Macedonia
}

\begin{abstract}
Videoconferencing technology is a successful tool for expanding possibilities for collaborative and distance learning, while bridging the distance between the teacher and students, providing time and cost savings. Recently, the focus in literature and practice for quality requirements are shifting from deterministic behavior of the infrastructure in videoconferencing learning environments to students' Quality of Experience, as subjective measure that involves human dimensions. Hence, this study evaluates the impact of different Quality of Service mechanisms utilized in the infrastructure on students' Quality of Experience in videoconferencing learning environments. It involved 263 faculty students that participated in $\mathbf{4 2}$ learning sessions via videoconferencing during their academic activities, while the infrastructure was subjected to Quality of Service mechanism in the network, as well as application enhancement in the videoconferencing platform, or both. The performance counters from the technical equipment and results from the survey regarding students' perceived experience, showed definite Quality of Service to Quality of Experience correlation. When network and application Quality of Service were considered complementary, students' Quality of Experience was in average 18.5\% higher compared to network and $15 \%$ to application Quality of Service implementations. Similarly, best technical performance was achieved when both mechanisms were consider as a whole, such as $34 \%$ decrease in average transmit delay compared to application and $62.5 \%$ to network Quality of Service mechanisms, etc. Finally, application controls had greater impact on perceived students' Quality of Experience than the network ones, which correlated to performance behavior of the infrastructure.
\end{abstract}

Keywords: Videoconferencing, learning environments, Quality of Service, Quality of Experience, Quality of Service/Quality of Experience correlation.

\section{INTRODUCTION}

Distance learning educational systems have developed rapidly in recent years and have become more popular in public and private institutions, while applying different forms of electronically supported teaching and learning (Bozkurt et al., 2015; Harris \& Krousgrill, 2008; Simonson, Smaldino, \& Zvacek, 2014; Zawacki-Richter \& Anderson, 2014). Latest technologies that offer different options for distance education are quickly adopted in order 
to promote additional values in the educational area. The educational process over distance involves different pedagogical and methodical approaches, which strive to reach an optimal level of perceived student knowledge according to students' potential. Hence, knowledge transfer is performed via number of learning methods, like self-paced learning with prerecorded audio and video materials, videoconferencing, tele-presence, web-based instructions, utilization of mobile devices, etc. (Bouhnik \& Marcus, 2006; Lawson et al., 2010; Malinovski et al., 2014; Xiong et al., 2017; Huang et al., 2016).

Videoconferencing-based educational systems can enable students in one or many locations, to watch and listen to an instructor in real time, and maintain interactivity with those remote locations. It is a mature technology that can be used in the distance learning process to provide instructor-student or student-student interaction (Clawson et al., 2016; Harris \& Krousgrill, 2008; Lawson et al., 2010; Malinovski et al., 2014; Neeman et al., 2010). If it is used appropriately, videoconferencing can be cost-effective way for educational institutions to deliver successful educational experience to an expanded student population. Videoconferencing-based systems are relatively easy for end-users to operate, while establishing connections between remote locations. When in a call, the distributed team members are "virtually present" in same environment. Still, the usability of a videoconferencing session is closely connected to performance of the technological equipment and the underlying transport network, which influence the overall quality of the process (Borodakiy et al., 2015; Chen, Farley, \& Ye, 2004; Chodorek et al., 2017). Large amount and different types of data packets within the network that facilitates a videoconferencing session may introduce bottlenecks at certain part, so appropriate measures must be taken in advance to avoid the problems that may occur and provide stable, efficient, cost-effective solutions.

Quality of Service (Q०S) is a mechanism that manages packet loss, delay and jitter in the infrastructure during data stream transport from the source to the destination. ITU-T has developed several recommendations that define QoS and Performance (i.e. ITU-T E.800E.899, G.1000-G.1999, Y.1500-Y.1599, Y.2100-Y.2199 series) and Transmission Media Characteristics (ITU-T G.6000-G.6999), which can be applied on infrastructures that support different process, to maintain appropriate level of service and meet end-user expectations. Similarly, QOS provisioning and controls are necessary in a videoconferencing learning environments to provide predictable, stable and measurable behavior of the infrastructure (Hossain, 2014; Sudarsono et al., 2016). Hence, the performance of the possible heterogeneous infrastructure must suit the basic necessities for rich audio and video media during an interactive videoconferencing session. On the other hand, QoS is a technical measure that deals with behavior of protocols, services and applications within the infrastructure, which might or might not significantly influence students' expectations for quality, while participating in a videoconferencing learning environment. In like manner, Nikravesh et al. (2016) state that QoS mechanism in the network does not always directly influence users' experience, since changes in a video streaming application's frame rate may compensate changes in packet loss rate. Malinovski et al. (2014) have found moderate support between technical performance and students' experience while using videoconferencing-based educational system, which means small variations in technical quality might not be detected by the students. Hence, number of studies have focused on students' Quality of Experience (QOE) as a full-scale evaluation of the learning process in a terms of students subjective experience and quality expectations (Aldrich et al., 2000; De Marez, \& De Moor, 2007; Kalliris et al., 2014; Karadimce \& Davcev, 2014; Malinovski et al., 2014; Van Moorsel, 2001; Vasileva-Stojanovska et al., 2015). Still, having in mind the variety of QOS mechanisms and the link between technical performance of the videoconferencing infrastructure (including applied QOS) and students' QoE, research studies that provide information for the impact of different forms of QOS on students' QoE can provide benefit to educational institutions that use or plan to implement similar learning methods.

This study aims to analyze the influence of different QoS mechanisms that can be implemented in the infrastructure of videoconferencing-based learning system on 
students' QoE involved in the learning process. Even though students' QoE is a complex and multidimensional measure influenced by different factors (Laghari et al., 2017; Malinovski et al., 2014; Vasileva-Stojanovska et al., 2015), the study covers only the link between QoS and QoE to provide information whether different QoS controls can be detected by students and will further influence their experience. Hence, it researches traditional QoS mechanisms in the network, as well as application enhancement for QoS in the videoconferencing platform. These QoS measures are utilized in multiple learning videoconferencing sessions, while real-time feeds from the infrastructure devices and instruments are correlated with students' perceived QoE. The results aim to help stakeholders of education institutions that use videoconferencing in their practice to understand the necessity for proper QOS implementation, which can further affect students' satisfaction and positive QoE.

\section{THEORETICAL BACKGROUND}

Different researchers have focused on QoS provisioning and controls that can enhance performance of the system. Some studies are focusing on the network, where proper traffic identification and classification can be applied (Kilinc \& Andersson, 2014; Lee \& Copeland, 2009; Richards et al., 1998; Yan et al., 2016; Zander, Nguyen, \& Armitage, 2005). These QoS mechanisms aim to increase the quality of network delivery (jitter, delay and packet loss) via prioritization and resource reservation, while providing satisfactory service to endusers. Other studies try to implement transparency for the existing QoS mechanisms and introduce additional QOS middleware positioned in the application layer in servers or devices into the infrastructure (Egilmez, Civanlar, \& Tekalp, 2013; Nahrstedt et al., 2001; Nikravesh et al., 2016; Romero, 2010; Shirazi, Kumar, \& Sung, 2004, Yim, Son, \& Lee, 2016). Hence, they target the quality of delivered content via the utilized application, such as audio/video synchronization, terminal handling of media flows, video error concealment, etc. The first group is referred as network-based Quality of Service (NQOS), while the second application-based Quality of Service (AQOS).

During a videoconferencing-based session, NQOS aims to ensure reliable delivery of multimedia data packets over a converged transport infrastructure (Chen, Farley, \& Ye, 2004; Lee et al., 2007; Rajkumar et al., 1997; Vasileva-Stojanovska et al., 2015). Different types of data streams that are usually present within the converged network where videoconferencing based e-learning systems are placed, could introduce bottlenecks at certain part of the infrastructure. Hence, NQOS classification and provisioning scheme has to be designed and tested in advance, before videoconferencing e-learning sessions are utilized in the learning process, so latency, jitter, and packet loss would be avoid as possible. AQOS relates to measures embedded within an application that preserve the quality of its intended use. It has increased popularity in recent years in different type of video communications over distance, utilized to minimize the effects of the packet delay and loss while responding dynamically with measures in the application (Agboma \& Liotta, 2007; Nikravesh et al., 2016; Pathak, Singh, \& Patel, 2016; Rajani, Khaparde, \& Ghuge, 2017; Siller \& Woods 2003; Usman et al., 2015). Hence, AQoS mechanism during videoconferencing can improve call signaling, media flows termination, for both video and audio, as well as quality of video signal via recovery of small blocks of data using the information from neighboring ones that were already received.

ITU-T (2007) has define QoE as overall acceptability of an application or service, as perceived subjectively by the end-user. Laghari \& Connelly (2012) have perceived the term QoE as a blueprint of human subjective quality needs and experiences arising from interaction of a person with technology in a particular context. According to Yan et al. (2016) QoE ultimately determines the user-perceived service quality, while Malinovski et al. (2014) use QoE to determine students' subjective experience and quality expectations during distance education activities. Despite the importance of QoE, Nikravesh et al. (2016) have come to conclusion that a single mapping from QoS to QoE values does not exist, having in mind the wide variance of QoS measures across different applications, e.g., frame rate in video conferencing and page load time in web browsing, etc. Still, they emphasize 
that QoS to QoE correlation is important, so QOS mechanisms can be adjusted for increased end-users' QOE from certain service, when their low QOE should be improved to tolerable levels. There are number of studies that explore the link between QoS and QoE in different contexts (Agboma \& Liotta, 2007; Chen, Wu, \& Zhang, 2015; Kim \& Choi, 2010; Laghari et al., 2017; Kuipers, et al., 2010; Siller \& Woods, 2003; Stankiewicz,\& Jajszczyk, 2011), but only few studies focus on QOS and students' QOE during videoconferencing learning sessions, mostly as an addition to other factors influencing QoE (Malinovski et al., 2014; Vasileva-Stojanovska et al., 2015). Therefore, these limited attempts to show a correlation between QoS and student's QoE in videoconferencing learning environments open new prospects for research on this topic that can be applied in similar distance learning programs.

\section{METHODOLOGY}

\section{Participants and Design}

This study included information technologies students in the several Universities in Republic of Macedonia, positioned in different parts of the country, as well as one University in Italy. The study were organized during 2013-2016, in three academic years, with students attending "traditional" classroom courses, as well as distance learning lectures with an aid of a videoconferencing platform, which were analyzed during the research. Hence, the study involved 263 students, $65 \%$ male and $35 \%$ female, with average of $\mathbf{2 1}$ years and students of all undergraduate and postgraduate years.

The videoconferencing infrastructure that was used to facilitate videoconferencing-based learning environment covered different sites/Universities with suitable classrooms, professional platform and a central videoconferencing management control site. These sites are connected with a live, IP transport infrastructure, which provides communication between different Universities for day-to-day activities. It represents a converged network, which consolidates different media, such as data, video and voice into a single infrastructure. This system encompasses advanced video coding standards (MPEG4, H.263, H.264 etc.), which are used to compress rich media on the top of the underlying IP transport infrastructure. H.323 was used for call signaling/control, multimedia transport / control for point-to-point and multi-point conferences (Saxena, Jasola, \& Sharma, 2006), which enabled the remote video conferencing endpoints to participate as a closed usergroup. Each classroom was equipped with point of presence devices, teacher/student camera, coding/decoding engine, display or projector, and proper sound system (microphone and speakers). Hence, this professional videoconferencing infrastructure was utilized in 42 learning sessions between different sites (two, sometimes three in same session), conducted within the standard academic activities in three years. Each learning session started with $\mathbf{3 0}$ minutes presentation from lecturer in one site, followed by $\mathbf{3 0}$ minutes presentation from lecturer at the other site. The learning sessions were concluded with discussion via videoconferencing, which promoted students cooperation and opportunity for students to share educational expertise with colleagues. In our methodological approach, we have implemented three QoS mechanisms, during random, equally spread learning sessions:

> QoS controls and provisioning implemented within the network (NQoS);

$>$ application enhancements of the videoconferencing platform for improved performance (AQOS);

$>$ both, NQOS and AQOS during videoconferencing sessions.

The students participated in several videoconferencing learning sessions, with the different QoS controls, so they can express their QoE from the learning sessions. Students were not aware of the technical setup, so the produced results could provide adequate information for the relation between utilized QoS mechanism and students' QoE. 


\section{Research Procedure}

The transport infrastructure in the environment where the study was conducted has sophisticated networking devices (routers) at different points of the network, including ones that can experience traffic saturation, so their flow recognition and provisioning capabilities can be programmed as NQOS according to the learning objectives and tested for results. While designing NQoS controls within the network we have implemented: (1) discovery phase, which was running for several weeks in advance, gathering information/statistics for the traffic across the live infrastructure, including test videoconferencing streams as planned for the learning sessions and (2) classification and provisioning phase, which used the gathered information of the previous phase, to classify the traffic according to the behavior of the network (Li et al., 2017; Szigeti et al., 2013). Hence, the networking infrastructure and its predefined policy for NQOS provisioning was adjusted to follow the desired classification and handling of rich media, so the videoconferencing flows (signaling and voice/video media) could receive as little delay and jitter as possible, with minimal packet loss (Figure 1).

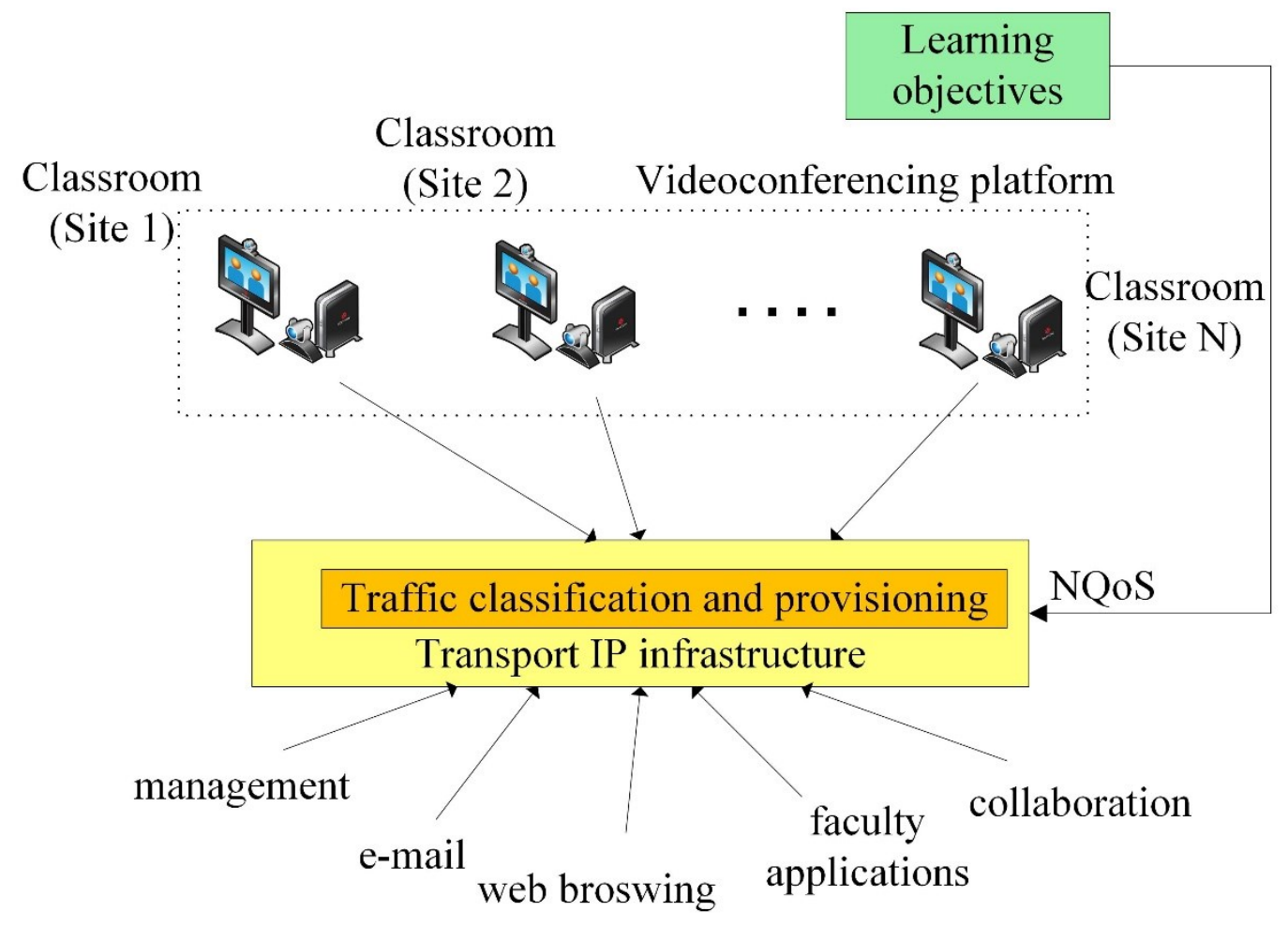

Figure 1. NQoS mechanism within the transport network

The videoconferencing platforms used during the learning sessions has different application based mechanisms that can increase QOS during the sessions (AQOS). The H.323 protocol used for call signaling, maintenance and termination of the videoconferencing sessions, was optimized related to delay and reliability. The signaling reliability was increased through retransmition of signal messages, after a minimal timeout, which generally improved the reliability and has speed up the communication. AQoS also enhanced the rich media handling through the videoconferencing platform. Hence, dynamic jitter buffers were used for compensation of inter-arrival packet jitter and dynamic bandwidth allocation to adjust the video bit rate and bandwidth during video communications, in order to eliminate packet loss (Dixit et al., 2013; Parakh \& Jagannatham, 2012). In addition, the videoconferencing platform used in the study has vendor specific algorithm that provides video error concealment (Pathak, Singh, \& Patel, 2016; Rajani, Khaparde, \& Ghuge, 2017; Usman et al., 2015). This technology was designed 
to maintain the quality of videoconferencing session over a live transport infrastructure, by immediately recognizing and taking action on video packet loss. With video error concealment, the video stream is coded in macro blocks, which are than randomized and sent through the transport infrastructure. Therefore the macro blocks, that are part of a same video frame, are sent in different packets. When a packet loss occurs during a videoconferencing session, the video concealment algorithm needs to compensate for the isolated missing macro blocks, since the codec can reproduce the lost micro blocks from the others, which are received within the packets that were not lost. These AQoS controls complement each other, so they were utilized to provide improved quality of the systems' performance during the learning sessions. Figure 2 illustrates the position of AQoS mechanism within the system infrastructure.

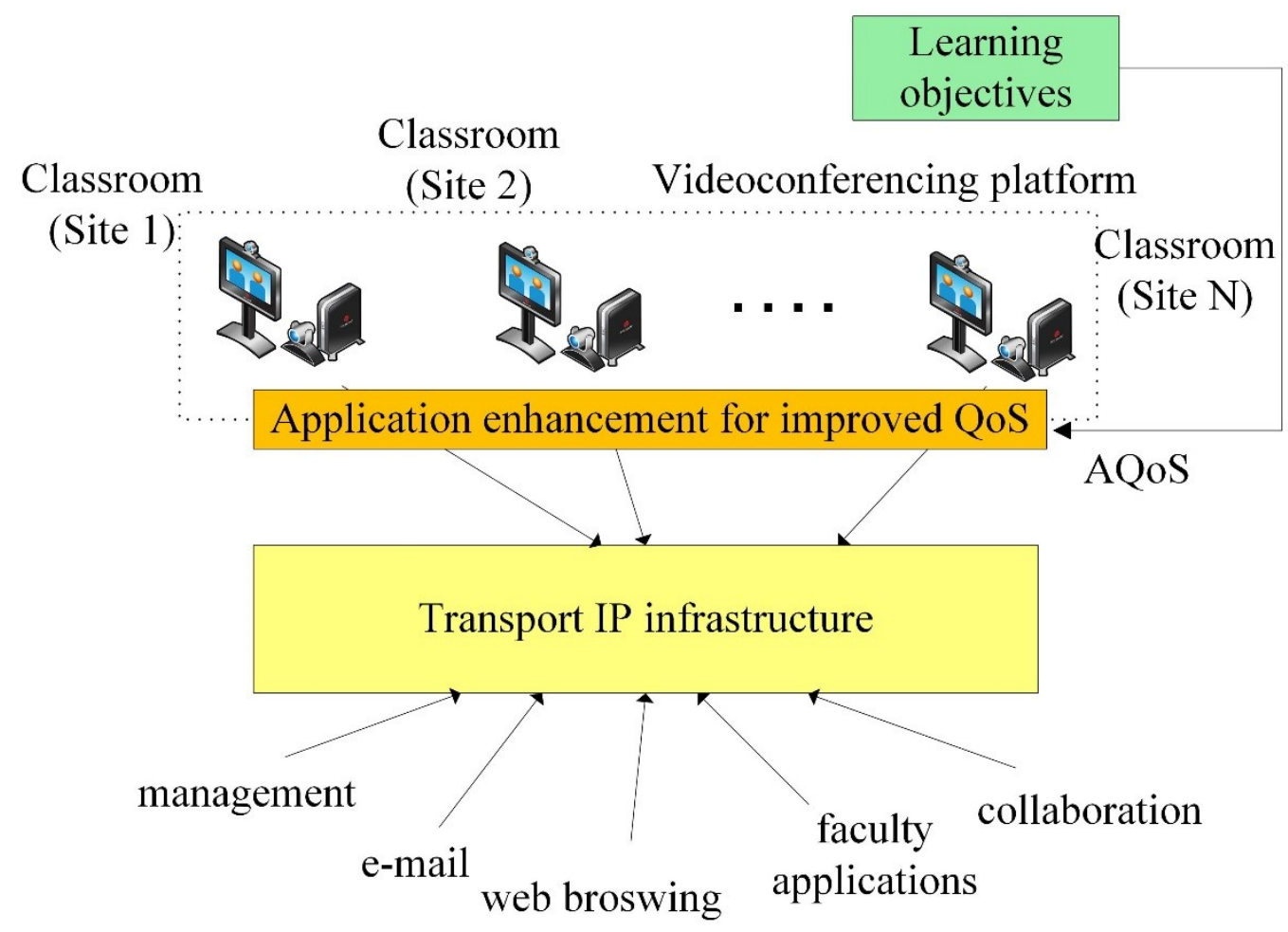

Figure 2. AQOS mechanism within the videoconferencing platform

\section{Data Collection}

The system and videoconferencing platform have a central site with multipoint control unit (MCU), which functions as videoconferencing interconnect-bridge and multimedia gateways/gatekeepers. The centralized management provided real time feed from instruments and sensors, which facilitated proper session monitoring, log generation, measurement selection and preparation of evaluation information on several aspects. Therefore, we were able to gather necessary technical information regarding packet loss, delay and jitter in the infrastructure during each learning session, so we can analyze the system's performance during NQOS and AQOS only, as well as both NQOS and AQOS implementations. Hence, we further used this information during analysis and correlation with students' perceived QoE.

As indicated in Laghari \& Connelly (2012) in their analysis of QoE frameworks, QoE is usually gathered via interviews, web based surveys and questionnaires, to obtain 
subjective information from users about product or service. In line with VasilevaStojanovska et al. (2015) that students' QOE derives from the complete system's effect on the students, influenced by their perception of the technical performance as well as their expectations for the learning session in general, we have designed a web based survey to gather students' opinion after each session with two sections. The first section of the survey contained direct questions regarding students' perception of technical quality (video, audio, their synchronization, etc.), while the second section focused on student's opinions for the learning session, which was to certain extend indirectly connected the technical environment. Survey's questions were phrased on a ten-point Likert scale (Likert, 1931), where 1 = strongly disagree and $\mathbf{1 0}=$ strongly agree. Table 1 lists research variables and questions from the evaluation survey used during the study.

Table 1. Structure of the evaluation survey

\begin{tabular}{|c|c|c|}
\hline Section & Question (QoE research variable) & Source \\
\hline $\begin{array}{l}\text { Section A: } \\
\text { Evaluation of } \\
\text { the technical } \\
\text { environment }\end{array}$ & $\begin{array}{l}\text { A1. The videoconferencing provided quality video } \\
\text { performance } \\
\text { A2. The videoconferencing provided high quality audio } \\
\text { A3. I did not notice loss of synchronization between the } \\
\text { video and audio during the session } \\
\text { A4. I received enough information to participate in the } \\
\text { videoconferencing session } \\
\text { A5. I did not notice technical inconvenience during the } \\
\text { session }\end{array}$ & $\begin{array}{c}\text { Student } \\
\text { survey }\end{array}$ \\
\hline $\begin{array}{l}\text { Section B: } \\
\text { General aspect } \\
\text { of the learning } \\
\text { session }\end{array}$ & $\begin{array}{l}\text { B1. I observed education advantages because } \\
\text { videoconferencing was introduced in the learning session } \\
\text { B2. I did not experience lowering of the attention level } \\
\text { during the session } \\
\text { B3. I found it difficult to follow teacher explanation } \\
\text { through the videoconferencing } \\
\text { B4. I did not find difficulties to concentrate during the } \\
\text { session } \\
\text { B5. I was satisfied with the organization of the session }\end{array}$ & $\begin{array}{c}\text { Student } \\
\text { survey }\end{array}$ \\
\hline
\end{tabular}

The educational institutions that participated in the study required course evaluation survey after each session, so students' response rate was $100 \%$. Students' personal data and privacy was protected at all time, and the teacher did not influence students' decision and evaluation criteria. Having in mind that students' QOE is influenced by different factors, we have designed the questions to obtain students' opinion on different aspects and ideally produce information that can be correlated with QOS results during the videoconferencing learning sessions.

\section{RESULTS}

The information gathered for the technological performance of the equipment contains objective values, which depend solely on utilized QoS mechanism, videoconferencing platform and transport infrastructure. Hence, from the central site we obtained negotiated video/audio codec during each learning session depending of the current state of the infrastructure, call rate, packet delay and jitter, as well as packet loss during NQoS, AQos and both implementations. 
Table 2. Statistical information for technical performance from several videoconferencing sessions

\begin{tabular}{|c|c|c|c|c|c|c|c|c|c|c|c|}
\hline Date & Duration & Type & Call rate & $\begin{array}{c}\text { Audio } \\
\text { protocol }\end{array}$ & $\begin{array}{c}\text { Video } \\
\text { protocol }\end{array}$ & $\begin{array}{l}\text { Video } \\
\text { format }\end{array}$ & $\begin{array}{c}\text { Average } \\
\text { packet } \\
\text { loss \% } \\
(\mathrm{Tx} / \mathbf{R x})\end{array}$ & $\begin{array}{c}\text { Max. } \\
\text { delay } \\
\text { msec } \\
(\mathrm{Tx} / \mathbf{R x})\end{array}$ & $\begin{array}{c}\text { Average } \\
\text { delay } \\
\text { msec } \\
\text { (Tx/Rx) }\end{array}$ & $\begin{array}{c}\text { Max. } \\
\text { jitter } \\
\text { msec } \\
\text { (Tx/Rx) }\end{array}$ & $\begin{array}{c}\text { Average } \\
\text { jitter } \\
\text { msec } \\
\text { (Tx/Rx) }\end{array}$ \\
\hline $31 / \mathrm{May} / 2013$ & $00: 33: 41$ & H323 & 1920Kbps & Siren22 & H.264 & 4CIF & $0.1 / 0.6$ & $43 / 43$ & $24 / 24$ & $9 / 12$ & $1 / 2$ \\
\hline $02 / J u n / 2013$ & $00: 42: 53$ & H323 & 1024Kbps & G.722.1c & H.264 & 2CIF & $1.4 / 0.5$ & $200 / 184$ & $88 / 85$ & $8 / 15$ & $3 / 6$ \\
\hline $04 / J u n / 2014$ & $00: 36: 29$ & $H 323$ & $1024 \mathrm{Kbps}$ & G.722.1C & H.264 & 4CIF & $1.8 / 2.66$ & $439 / 439$ & $196 / 203$ & $40 / 40$ & $15 / 12$ \\
\hline 24/Jun/2014 & $00: 57: 43$ & H323 & $1920 \mathrm{Kbps}$ & Siren22 & H.264 & 4CIF & $1.3 / 1.8$ & $213 / 213$ & $55 / 57$ & $30 / 34$ & $13 / 18$ \\
\hline $08 / 0 \mathrm{ct} / 2015$ & $00: 33: 53$ & H323 & $1920 \mathrm{Kbps}$ & Siren22 & H.264 & 4CIF & $0.16 / 0.1$ & $41 / 41$ & $21 / 22$ & $31 / 7$ & $2 / 2$ \\
\hline $18 /$ Nov/2015 & $00: 41: 04$ & $H 323$ & $1920 \mathrm{Kbps}$ & Siren22 & H.264 & 4CIF & $0.06 / 0.1$ & $20 / 20$ & $6 / 6$ & $10 / 4$ & $2 / 1$ \\
\hline $03 / \mathrm{Dec} / 2015$ & $00: 26: 06$ & H323 & $1920 \mathrm{Kbps}$ & Siren22 & H.264 & 4CIF & $0.8 / 1.86$ & $161 / 161$ & $129 / 129$ & $35 / 39$ & $15 / 19$ \\
\hline $13 / J a n / 2016$ & 02:04:19 & H323 & 1920Kbps & Siren22 & H.264 & 4CIF & $0.4 / 0.3$ & $60 / 60$ & $40 / 40$ & $16 / 8$ & $8 / 2$ \\
\hline
\end{tabular}

Table 2 shows technical information from several videoconferencing sessions for better illustration of the technological parameters that were included in the study, while Table 3 shows summarized statistical information for these parameters, grouped by the utilized QoS mechanism.

Table 3. Summarized statistical information for technical performance, grouped by QoS mechanism

\begin{tabular}{l|ccccc}
\hline $\begin{array}{l}\text { QoS } \\
\text { Mechanism }\end{array}$ & $\begin{array}{c}\text { Average } \\
\text { packet loss } \\
\%(T x / R x)\end{array}$ & $\begin{array}{c}\text { Maximum } \\
\text { delay } \\
\text { msec }(\mathrm{Tx} / \mathrm{Rx})\end{array}$ & $\begin{array}{c}\text { Average } \\
\text { delay msec } \\
(\mathrm{Tx} / \mathrm{Rx})\end{array}$ & $\begin{array}{c}\text { Maximum } \\
\text { jitter } \\
\text { msec }(\mathrm{Tx} / \mathrm{Rx})\end{array}$ & $\begin{array}{c}\text { Average jitter } \\
\text { msec (Tx/Rx) }\end{array}$ \\
\hline NQOS & $\mathbf{0 . 8 / 1 . 2}$ & $439 / 439$ & $88 / 99$ & $40 / 41$ & $10 / 9$ \\
AQOS & $0.5 / 0.6$ & $178 / 180$ & $50 / 50$ & $35 / 35$ & $6 / 6$ \\
NQOS and & $0.2 / 0.3$ & $70 / 65$ & $33 / 33$ & $24 / 30$ & $4 / 6$ \\
AQOS & & & & & \\
\hline
\end{tabular}

These results show that the videoconferencing platform, endpoints and transport network were working satisfactory, without significant problems while establishing and maintaining a quality videoconferencing session. Still, since the system was operating on a live converged network that carries different type of traffic flows, congestion and small issues were detected at certain intervals. With NQOS in place and its traffic discovery phase, the networking devices were able to gather information regarding the actual network itself, while the classification and provisioning steps for videoconferencing privileged alignment and treatment had also benefit from this phase. Additionally, the system was performing better with AQOS compared to NQOS mechanism only. The application enhancement within the videoconferencing platform were able to coup with the sudden traffic saturation within the infrastructure and provide better performance in avoiding packet loss, latency and jitter during the videoconferencing sessions. Still, both QoS mechanisms were able to provide the best performance results while working complementary, providing premium treatment for the videoconferencing rich media, from one end-point in one site, through the transport network, to the other sites.

Additionally, we have analyzed students' response for their perceived QoE after each videoconferencing learning sessions, grouped by the utilized QOS mechanism in the infrastructure. Thus, we obtained comprehensive QoE results as their subjective opinion for the technical performance (section $A$ ) and general aspects of the learning sessions (section B). Figure 3 and Figure 4 students' QoE expressed as Mean Opinion Score (MOS) for each research variable, grouped by utilized QOS mechanism and survey section. 


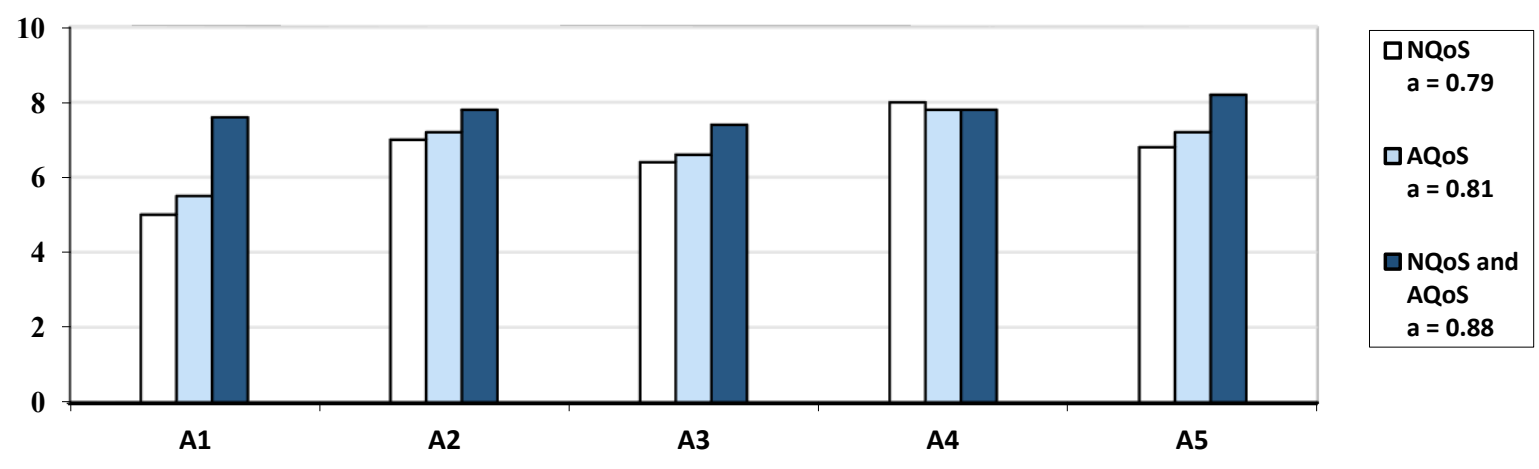

Figure 3. Results from students' evaluation of technical performance (section A), where $\mathbf{a}=$ Cronbach's alpha

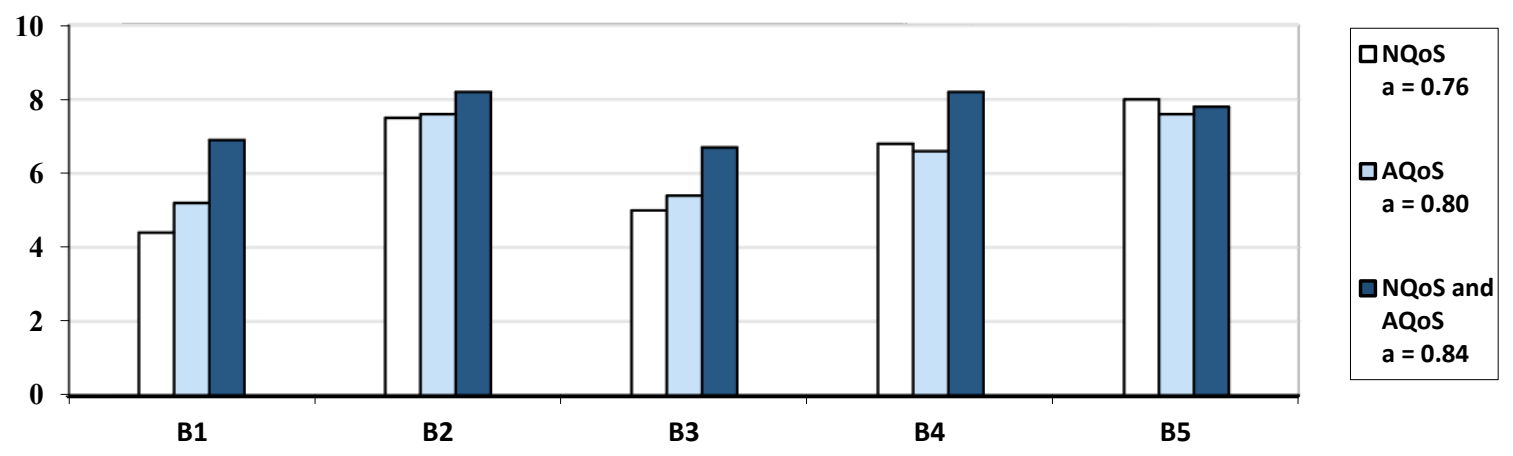

Figure 4. Results from students' evaluation for general aspects of the learning sessions (section B), where $\mathrm{a}=$ Cronbach's alpha

We have used Cronbach's alpha test to assess data validity and internal consistency of the research items for each section of students' responses, during different QoS implementations. As indicated in Figure 3 and Figure 4, the resulting Cronbach's values for each group were sufficiently above the desired threshold of 0.7 (Nunnally \& Bernstein, 1994), which verifies the scale reliability for measurable items in each section, having in mind that high alpha values do not imply that the measure is unidimensional. In addition, MOS results of students' self-reporting information show that students have positively accepted the use of videoconferencing in the learning environment. The interaction between different sites and collaboration with other students and faculties contributed to positive attitude towards this learning method. Most importantly, the results show correlation and link between objective technical performance obtained from the infrastructure (as QoS result) and subjective students' QoE. Even though students were not aware of the technological setup during each learning session, their subjective opinion was reflecting the actual performance of the videoconferencing platform and transport network. The level of students' perceived QoE (technical view and general aspects) was highest during NQOS and AQOS implementation, which completely correlates to objective information gathered from the equipment itself. Furthermore, students have shown slightly higher QoE level when AQOS was used compared to NQOS, which was similar to the difference in statistical information for technical performance. Consequently, these results altogether support research claims for close relation between QOS and QoE in videoconferencing learning environment.

\section{DISCUSSIONS}

This study confirms the finding of different research endeavors (Agboma \& Liotta, 2007; Chen, Wu, \& Zhang, 2015; Kim \& Choi, 2010; Laghari \& Connelly, 2012; Siller \& Woods, 2003; Stankiewicz \& Jajszczyk, 2011) that emphasize the importance of QoS to QoE 
correlation, so QoS mechanisms can be adjusted or improved in order to increase end-users' perceived QoE. While demonstrating a connection between utilized QoS mechanisms in the infrastructure and students' QoE during videoconferencing learning sessions, it provides contribution to literature that can be replicated in similar distance learning activities. Hence, the objective QoS and system's performance were measure from different aspects, while covering concepts, parameters and methods needed to manage interactions between videoconferencing applications, students' terminals at each of the sites and the underlying transport infrastructure in a form of NQOS, AQOS, or both. Via the information supplied in a form of students' experience and the link to different QoS controls within the system, the study provides conversions from technical parameters to human experience.

\section{CONTRIBUTIONS}

In line with similar studies that understand QOE as multidimensional concept (Aldrich et al., 2000; De Marez, \& De Moor, 2007; Karadimce \& Davcev, 2014; Laghari \& Connelly, 2012; Malinovski et al., 2014; Nikravesh et al., 2016; Siller \& Woods, 2003), students' QoE in videoconferencing learning environments is conceived as a multidimensional concept that consists of both objective (e.g., bit rates, packet loss, latency, performance etc.) and subjective (e.g., user-related satisfaction, positive experience) aspects. Recognizing that QoE is influenced by different factors, most of these factors were kept constant during the learning sessions (same students participated in different classes, as well as same professors were included during various QoS implementations, the subject materials were on similar topics, etc.), so the results can show whether the difference in technical performance is correlated with the difference in students' QoE. Hence, the study's findings show that ultimately both NQOS and AQOS mechanisms should be used, since they can properly position the infrastructure to facilitate increased level of students' QoE. They complement the results in Vasileva-Stojanovska et al. (2015) that indicate NQoS as one of the factors affecting students' QOE in distance learning environments, while providing additional correlation for AQOS and both NQOS/AQOS implementations and students' experience. Despite the findings in Siller \& Woods (2003) that state that NQoS controls have bigger impact on perceived end-user QOE than AQOS for multimedia services, this study has shown that AQOS should be also considered, optimally complimenting NQoS, to increase students' QOE in videoconferencing learning environments.

In line with the latest shift in literate and practice from QoS to QoE (Agboma \& Liotta, 2007; Chen, Wu, \& Zhang, 2015; Jarschel, et al., 2011; Laghari et al., 2017; Zhang \& Ansari, 2011), the results from this study can benefit organizations that use or plan to introduce videoconferencing in the learning environment. These findings are helpful in QOS/QOE correlation, since educational institutions that fail to understand the importance of the students' QoE, affective and meaningful interaction with technology behind the service, and the ways to improve it, will be left behind in future development and proper positioning in the distance learning area.

\section{CONCLUSION}

The study follows a user-oriented approach while focusing on positive students' experience in videoconferencing learning environment, a key driver of technology acceptance, adoption and usage behavior. Hence, we have presented our findings for the link between different QOS mechanisms and students' QOE in videoconferencing learning environment. In our research activities, we have included 263 students that participated in 42 learning sessions via videoconferencing, while utilizing NQOS, AQOS and both NQOS/AQOS controls in the infrastructure. After each session, students' expressed their experience for the perceived technical performance and general aspect of the videoconferencing learning environment. The finding in this study have determined that:

$>$ There is a link between objective technical parameters provided by QoS mechanisms and subjective students' indicators for QoE in videoconferencing learning environments; 
$>$ Combined NQOS and AQoS implementation provide best results for technical performance in the infrastructure, which correlates with highest level of students' QOE compared to videoconferencing learning sessions when only NQoS or AQOS mechanisms are utilized;

$>$ AQOS should not be neglected, even when is used as only mechanism, since in specific environments it can provide better technical performance than NQoS, which ultimately correlates with students' QoE.

In line with studies in literature that focus on QOS and QoE in different contexts, this study tries to bridge the QOS/QOE gap in videoconferencing learning environments while providing helpful information to educational organizations to optimize their network and application resources driven by students' perceived QoE. Henceforth, this study opens up new avenues for future research, so researches can use obtained results while trying to model factors (objective and subjective) predicting students' QOE in similar learning environments.

\section{BIODATA and CONTACT ADDRESSES of AUTHORS}

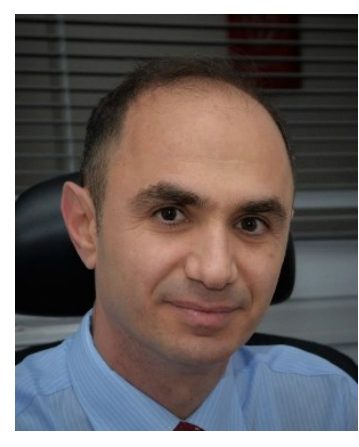

Assist. Prof. Dr. Toni MALINOVSKI completed his Master's degree in Computer Science at the Faculty of Electrical Engineering and Information Technologies, Ss. Cyril and Methodius University, Skopje (1998). He recived his PhD at the Faculty of Computer Science and Engineering, Ss. Cyril and Methodius University, Skopje (2015). Works at National Bank of the Republic of Macedonia and holds the position IT senior advisor. Also, he is professor at the Faculty of Information and Communication Technology, FON University, Skopje. His major research interests include IT and business process management, quality assurance, rich communication media, distance education and distributed systems.

Toni MALINOVSKI

Faculty of Information and Communication Technology, FON University

Kiro Gligorov b.b. 1000 Skopje, Macedonia

Phone: + 38922445555

E-mail: toni.malinovski@fon.edu.mk

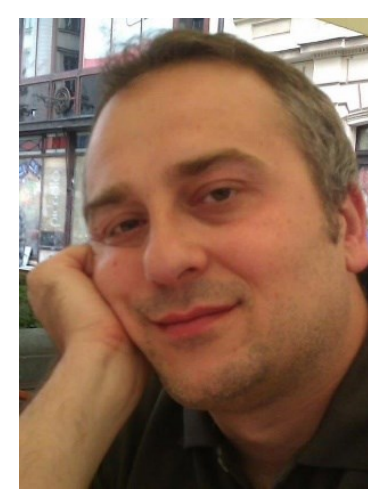

Prof. Dr. Vladimir TRAJKOVIK is full professor at University Ss Cyril and Methodius in Skopje, at the Faculty of Computer Science and Engineering. His research interests include: Information Systems Analyses and Design, e-governance and digital societies, ICT based Collaboration Systems and Mobile services with special focus on Educational Systems. He is program chair of Internet technologies in higher education international conference supported by IEEE UNESCO and SEFI. He has published 4 books as author or editor, 12 chapters in different books published by international publishers, as well as 35 journal and more than 120 conference papers. He has participated in more than $\mathbf{3 0}$ national and international ICT projects related to providing novel ICT based services. He has coordinated more than 10 of those projects.

\section{Vladimir TRAJKOVIK}

Faculty of Computer Science and Engineering

Ss. Cyril and Methodius University

Rudzer Boshkovikj 16, 1000 Skopje, Macedonia

Phone: + 38923088292

E-mail: trvlado@finki.ukim.mk 


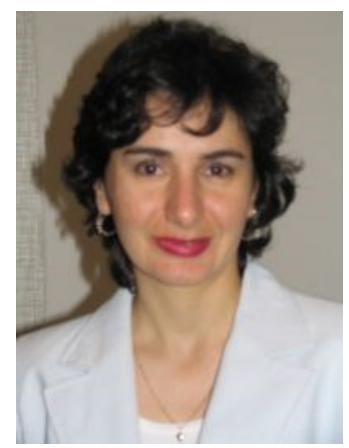

Dr. Tatjana VASILEVA-STOJANOVSKA completed her Master's degree at the Faculty of Electrical Engineering and Information Technology, Ss. Cyril and Methodius University - Skopje (2000). She received her PhD degree in Technical Sciences at the Faculty of Information Science and Computer Engineering, Ss. Cyril and Methodius University, Skopje, Republic of Macedonia (2015). Her main research interests covered distance education, intelligent agent technology, fuzzy logic, and Quality of Experience modeling. Her ongoing research is focused on Neuro-Fuzzy modeling, Business Intelligence and Digital Cryptography. Works at the National Bank of Republic of Macedonia.

Tatjana VASILEVA-STOJANOVSKA

Faculty of Computer Science and Engineering

Ss. Cyril and Methodius University

Rudzer Boshkovikj 16, 1000 Skopje, Macedonia

Phone: + 38923088292

E-mail: tatjanav@nbrm.mk

\section{REFERENCES}

Agboma, F., \& Liotta, A. (2007). Addressing user expectations in mobile content delivery. Mobile Information Systems, 3(3-4), 153-164

Aldrich, S. E., Marks, R. T., Frey, M. M., Goulde, M. A., Lewis, J. M., \& Seybold, P. B. (2000). What kind of the total customer experience does your e-business deliver. Patricia Seybold Group.

Borodakiy, V. Y., Samouylov, K. E., Gudkova, I. A., Markova, E. V., \& Last_Name, F. (2015). Algorithm for Calculating QoS Parameters of Video Conferencing and Video on Demand Services in Wireless Next Generation Networks. Journal of ICT Standardization, 3(1), 3-28

Bouhnik, D., \& Marcus, T. (2006). Interaction in distance- learning courses. Journal of the Association for Information Science and Technology, 57(3), 299-305

Bozkurt, A., Akgun-Ozbek, E., Yilmazel, S., Erdogdu, E., Ucar, H., Guler, E., Sezgin, S., Karadeniz, A., Sen-Ersoy, N., Goksel-Canbek, N., \& Dincer, G. D. (2015). Trends in distance education research: A content analysis of journals 2009-2013. The International Review of Research in Open and Distributed Learning, 16(1)

Chen, Y., Farley, T., \& Ye, N. (2004). QoS requirements of network applications on the Internet. Information Knowledge Systems Management, 4(1), 55-76

Chen, Y., Wu, K., \& Zhang, Q. (2015). From QoS to QoE: A tutorial on video quality assessment. IEEE Communications Surveys \& Tutorials, 17(2), 1126-1165

Chodorek, R. R., Chodorek, A., Rzym, G., \& Wajda, K. (2017, June). A Comparison of QoS Parameters of WebRTC Videoconference with Conference Bridge Placed in Private and Public Cloud. In Enabling Technologies: Infrastructure for Collaborative Enterprises (WETICE), 2017 IEEE 26th International Conference on (pp. 86-91). IEEE

Clawson, D., Korns, M., Decker, S., \& Piper, D. (2016, March). Cloud-based videoconferencing learning environments in Higher Education: The growing pains of synchronous learning in an asynchronous world. In Society for Information Technology \& Teacher Education International Conference (pp. 178-184). Association for the Advancement of Computing in Education (AACE)

De Marez, L., \& De Moor, K. (2007). The challenge of user-and QoE-centric research and product development in today's ICT-environment. Observatorio (OBS*), 1(3)

Dixit, A., Lannoo, B., Das, G., Colle, D., Pickavet, M., \& Demeester, P. (2013). Dynamic bandwidth allocation with SLA awareness for QoS in ethernet passive optical networks. Journal of Optical Communications and Networking, 5(3), 240-253 
Egilmez, H. E., Civanlar, S., \& Tekalp, A. M. (2013). An optimization framework for QoSenabled adaptive video streaming over OpenFlow networks. IEEE Transactions on Multimedia, 15(3), 710-715

Harris, D. A., \& Krousgrill, C. (2008). Distance education: New technologies and new directions. Proceedings of the IEEE, 96(6), 917-930

Hossain, M. S. (2014, February). QoS in web service-based collaborative multimedia environment. In Advanced Communication Technology (ICACT), 2014 16th International Conference on (pp. 881-884). IEEE

Huang, X., Chandra, A., DePaolo, C. A., \& Simmons, L. L. (2016). Understanding transactional distance in web-based learning environments: An empirical study. British Journal of Educational Technology, 47(4), 734-747

ITU-T (2007, January). Definition of Quality of Experience (QOE). International Telecommunication Union, Liaison Statement, Ref.: TD 109rev2 (PLEN/12)

Jarschel, M., Schlosser, D., Scheuring, S., \& Hoßfeld, T. (2011, June). An evaluation of QoE in cloud gaming based on subjective tests. In Innovative Mobile and Internet Services in Ubiquitous Computing (IMIS), 2011 Fifth International Conference on (pp. 330-335). IEEE

Kalliris, G., Matsiola, M., Dimoulas, C. A., \& Veglis, A. (2014, July). Emotional aspects in Quality of Experience and Learning (QoE \& QoL) of audiovisual content in mediated learning. In Information, Intelligence, Systems and Applications, IISA 2014, The 5th International Conference on (pp. 198-203). IEEE

Karadimce, A., \& Davcev, D. (2014, October). Model for collaborative and adaptive multimedia content delivery in a collaborative m-learning environment. In Collaborative Computing: Networking, Applications and Worksharing (CollaborateCom), 2014 International Conference on (pp. 431-434). IEEE

Kilinc, C., \& Andersson, K. (2014). A congestion avoidance mechanism for WebRTC interactive video sessions in LTE networks. Wireless Personal Communications, 774), 24172443

Kim, H. J., \& Choi, S. G. (2010, February). A study on a QoS/QoE correlation model for QoE evaluation on IPTV service. In Advanced Communication Technology (ICACT), 2010 The 12th International Conference on (Vol. 2, pp. 1377-1382). IEEE

Kuipers, F., Kooij, R., De Vleeschauwer, D., \& Brunnström, K. (2010, June). Techniques for measuring quality of experience. In International Conference on Wired/Wireless Internet Communications (pp. 216-227). Springer, Berlin, Heidelberg

Laghari, A. A., He, H., Zardari, S., \& Shafiq, M. (2017). Systematic Analysis of Quality of Experience (QOE) Frameworks for Multimedia Services. IJCSNS, 17(5), 121

Laghari, K. U. R., \& Connelly, K. (2012). Toward total quality of experience: A QoE model in a communication ecosystem. Communications Magazine, IEEE, 50(4), 58-65

Lawson, T., Comber, C., Gage, J., \& Cullum- Hanshaw, A. (2010). Images of the future for education? Videoconferencing: A literature review. Technology, Pedagogy and Education, 19(3), 295-314

Lee, M., \& Copeland, J. A. (2009, August). An adaptive end-to-end delay assurance algorithm with diffserv architecture in IEEE $\mathbf{8 0 2 . 1 1}$ e/IEEE $\mathbf{8 0 2 . 1 6}$ hybrid mesh/relay networks. In Computer Communications and Networks, 2009. ICCCN 2009. Proceedings of 18th Internatonal Conference on (pp. 1-6). IEEE

Lee, Y., Lou, J., Luo, J., \& Shen, X. (2007). An efficient packet scheduling algorithm with deadline guarantees for input-queued switches. IEEE/ACM Transactions on Networking (TON), 15(1), 212-225

Li, J., Yang, L., Fu, X., Chao, F., \& Qu, Y. (2017). Dynamic QoS Solution for Enterprise Networks Using TSK Fuzzy Interpolation. In 2017 IEEE International Conference on Fuzzy Systems (FUZZ-IEEE 2017) 
Likert, R. (1931). A technique for the measurement of attitudes. Archives of Psychology. New York: Columbia University Press

Malinovski, T., Vasileva, M., Vasileva-Stojanovska, T., \& Trajkovik, V. (2014). Considering high school students' experience in asynchronous and synchronous distance learning environments: QoE prediction model. The International Review of Research in Open and Distributed Learning, 15(4)

Nahrstedt, K., Xu, D., Wichadakul, D., \& Li, B. (2001). QoS-aware middleware for ubiquitous and heterogeneous environments. IEEE Communications magazine, 39(11), 140-148

Neeman, H., Severini, H., Wu, D., \& Kantardjieff, K. (2010). Teaching high performance computing via videoconferencing. ACM Inroads, 1(1), 67-71

Nikravesh, A., Hong, D. K., Chen, Q. A., Madhyastha, H. V., \& Mao, Z. M. (2016, August). QoE Inference Without Application Control. In Internet-QoE@ SIGCOMM (pp. 19-24)

Nunnally, J. C., \& Bernstein, I. H. (1994). Psychometric theory. 3rd ed. New York: McGraw-Hill

Parakh, S., \& Jagannatham, A. K. (2012, July). Game theory based dynamic bit-rate adaptation for H. 264 scalable video transmission in 4G wireless systems. In Signal Processing and Communications (SPCOM), 2012 International Conference on (pp. 1-5). IEEE

Pathak, K. C., Singh, S., \& Patel, J. N. (2016, December). Error detection and concealment algorithm for compressed video transmission. In Humanitarian Technology Conference (R1O-HTC), 2016 IEEE Region 10 (pp. 1-5). IEEE

Rajani, P. K., Khaparde, A., \& Ghuge, A. D. (2017, March). Implementation of Video Error Concealment Using Block Matching Algorithm. In International Conference on Information and Communication Technology for Intelligent Systems (pp. 357-364). Springer, Cham

Rajkumar, R., Lee, C., Lehoczky, J., \& Siewiorek, D. (1997, December). A resource allocation model for QoS management. In Real-Time Systems Symposium, 1997. Proceedings. The 18th IEEE (pp. 298-307). IEEE

Richards, A., Antoniades, M., Witana, V., \& Rogers, G. (1998). Mapping user level QoS from a single parameter. In Proceedings of the International Conference on Multimedia Networks and Services (MMNS '98)

Romero, D. (2008). Context-aware middleware: An overview. Paradigma, 2(3), 1-11

Saxena, P. C., Jasola, S., \& Sharma, R. C. (2006). Impact of VoIP and QoS on Open and Distance Learning. Turkish Online Journal of Distance Education, $\pi(3)$

Siller, M., \& Woods, J. (2003, April). Improving quality of experience for multimedia services by QOS arbitration on a QOE framework. In Proc. of the 13th Packed Video Workshop 2003

Simonson, M., Smaldino, S., \& Zvacek, S. M. (Eds.). (2014). Teaching and learning at a distance: Foundations of distance education. IAP

Stankiewicz, R., \& Jajszczyk, A. (2011). A survey of QoE assurance in converged networks. Computer Networks, 55(7), 1459-1473

Sudarsono, A., Siswanto, A., Iswanto, H., \& Setiawan, Q. (2016). Traffic Analysis of Quality of Service (Q०S) for Video Conferencing between Main Campus and Sub Campus in Laboratory Scale. EMITTER International Journal of Engineering Technology, 3(2)

Szigeti, T., Hattingh, C., Barton, R., \& Briley Jr, K. (2013). End-to-End QoS Network Design: Quality of Service for Rich-Media \& Cloud Networks. Cisco Press.

Usman, M., He, X., Xu, M., \& Lam, K. M. (2015, May). Survey of error concealment techniques: Research directions and open issues. In Picture Coding Symposium (PCS), 2015 (pp. 233-238). IEEE 